\title{
Perbandingan Metode Iterasi Jacobi dan Metode Iterasi Gauss-Seidel dalam Menyelesaikan Sistem Persamaan Linear Fuzzy
}

\author{
Sukarna ${ }^{1}$, Muhammad $\mathrm{Abdy}^{1}$, dan Rahmat ${ }^{1, \text { a) }}$ \\ ${ }^{1}$ Jurusan Matematika FMIPA Universitas Negeri Makassar, 90224 \\ a)rahmatpoetra2012@gmail.com
}

\begin{abstract}
Abstrak. Penelitian ini mengkaji tentang menyelesaian Sistem Persamaan Linear Fuzzy dengan Membanding kan Metode Iterasi Jacobi dan Metode Iterasi Gauss-Seidel. Metode iterasi Jacobi merupakan salah satu metode tak langsung, yang bermula dari suatu hampiran Metode iterasi Jacobi ini digunakan untuk menyelesaikan persamaan linier yang proporsi koefisien nol nya besar. Iterasi dapat diartikan sebagai suatu proses atau metode yang digunakan secara berulang-ulang (pengulangan) dalam menyelesaikan suatu permasalahan matematika ditulis dalam bentuk $x_{i}^{(k)}=\frac{1}{a_{i i}}\left(b_{i}-\sum_{j \neq i}^{n} a_{i j} x_{j}^{(k-1)}\right), i=$ $1,2, \ldots, n ; k=1,2,3, \ldots, n$. Pada metode iterasi Gauss-Seidel, nilai-nilai yang paling akhir dihitung digunakan di dalam semua perhitungan. Jelasnya, di dalam iterasi Jacobi, menghitung dalam bentuk $x_{i}^{(k)}=\frac{1}{a_{i i}}\left(b_{i}-\sum_{j=1}^{i-1} a_{i j} x_{j}^{(k)}-\sum_{j=i+1}^{r} a_{i j} x_{j}^{(k-1)}\right)$. Setelah mendapatkan Hasil iterasi kedua Metode tersebut maka langkah selanjutnya membandingkan kedua metode tersebut dengan melihat jumlah iterasinya dan nilai Galatnya manakah yang lebih baik dalam menyelesaikan Sistem Persamaan Linear Fuzzy.
\end{abstract}

Kata kunci: Sistem Persamaan Linear Fuzzy, Metode Itersi Jacobi, Metode Iterasi Gauss-Seidel.

Abstract. This study examines the completion of the Linear Fuzzy Equation System by Comparing the Jacobi Iteration Method and the Gauss-Seidel Iteration Method. The Jacobi iteration method is one of the indirect methods, which stems from an almost a method of this Jacobi iteration method used to solve linear equations whose proportion of large zero coefficients. Iteration can be interpreted as a process or method used repeatedly (repetition) in solving a mathematical problem written in the form $x_{i}^{(k)}=$ $\frac{1}{a_{i i}}\left(b_{i}-\sum_{j \neq i}^{n} a_{i j} x_{j}^{(k-1)}\right), i=1,2, \ldots, n ; k=1,2,3, \ldots, n$. In the Gauss-Seidel iteration method, the most recently calculated values are used in all calculations. Obviously, inside Jacobi iteration, counting in form $x_{i}^{(k)}=\frac{1}{a_{i i}}\left(b_{i}-\sum_{j=1}^{i-1} a_{i j} x_{j}^{(k)}-\sum_{j=i+1}^{r} a_{i j} x_{j}^{(k-1)}\right)$ After obtaining the result of second iteration of the Method then the next step compare both methods by seeing the number of iteration and the Error value which is better in solving Linear Fuzzy Equation System.

Keywords: Linear Fuzzy Equation System, Jacobi Itersi Method, Gauss-Seidel Iteration Method.

\section{PENDAHULUAN}

Sistem persamaan linear merupakan kumpulan persamaan linear yang saling berhubungan untuk mencari nilai variabel yang memenuhi semua persamaan linear tersebut. Sistem persamaan linier kadang muncul secara langsung dari masalah-masalah yang nyata sehingga membutuhkan proses penyelesaian. Menyelesaikan suatu persamaan linear adalah mencari nilai-nilai variabel 
yang memenuhi semua persamaan linear yang diberikan. Sistem persamaan linear biasanya terdiri atas $m$ persamaan dan $\mathrm{n}$ variabel. Sistem persamaan linear dapat ditulis dalam bentuk persamaan matriks $A x=b$ dengan semua entri-entri di dalam A dan b adalah bilangan riil.

Secara umum sistem persamaan linear dapat diselesaikan dengan dua metode yaitu metode langsung dan metode tidak langsung. Metode langsung biasanya disebut metode eksak, diantaranya metode eliminasi, subtitusi, dekomposisi LU, dekomposisi Cholesky, dan dekomposisi Crout. Metode tidak langsung biasanya disebut iterasi , diantaranya metode iterasi Jacobi, metode SOR, metode Gauss-Seidel. Metode iterasi Jacobi merupakan salah satu metode tak langsung, yang bermula dari suatu hampiran penyelesaian awal dan kemudian berusaha memperbaiki hampiran dalam tak berhingga namun langkah konvergen sedangkan Metode Gauss Seidel merupakan metode yang menggunakan proses iterasi hingga diperoleh nilai yang sesungguhnya. Metode ini menggunakan nilai awal dan pada proses selanjutnya menggunakan nilai yang sudah diketahui sebelumnya.

Konstanta dalam sistem persamaan linear biasanya berupa bilangan riil, namun seiring perkembangan ilmu matematika, konstanta dalam sistem persamaan linear dapat berupa bilangan fuzzy dan dapat diselesaikan dengan menggunakan metode yang sama. Fuzzy dapat diartikan sebagai kabur atau samar-samar, biasanya digunakan dalam masalah yang mengandung unsur ketidakpastian. Sistem persamaan linear dengan konstanta berupa bilangan fuzzy disebut sistem persamaan linear fuzzy . bentuk sistem persamaan linear fuzzy seperti sistem persamaan linear biasa, perbedaanya terletak pada unsur b . unsur b dalam sistem persamaan linear fuzzy merupakan bentuk parameter yang berada pada interval tertentu.

Penyelesaian sistem persamaan linear fuzzy telah dibahas oleh beberapa peneliti sebelumnya.Norita (2014) membahas tentang kajian sistem persamaan linear fuzzy dan solusi sistem persamaan linear fuzzy. Selajutnya Allahviranloo (2004) membahas penyelesaian sistem persamaan linear fuzzy dengan menggunakan metode Segitiga atas dan Segitiga bawah. Selanjutnya Kholifah (2014) membahas penyelesaian Sistem persamaan linear fully fuzzy dengan metode Gauss seidel.

Oleh karena itu, pada artikel ini membahas perbandingan dua metode yaitu metode Iterasi Jacobi dan Iterasi Gauss Seideldalam menyelesaikan sistem persamaan linear fuzzy dengan memperhatikan banyaknya iterasi dan nilai error pada suatu hasil iterasi tersebut.

\section{Sistem Persamaan Linear Fuzzy}

Sistem persamaan linear fuzzy adalah sistem persamaan linear yang berparameter fuzzy yang berada pada interval tertentu. Bentuk umum dari sistem persamaan linear fuzzy

$$
A \tilde{X}=\tilde{Y}
$$

Sistem persamaan linear fuzzy dapat dijelaskan

$$
\begin{array}{cccc}
a_{11} \tilde{x}_{1}+ & a_{12} \tilde{x}_{2}+ & \cdots+ & a_{1 n} \tilde{x}_{n}=\tilde{y}_{1} \\
a_{21} \tilde{x}_{1}+ & a_{22} \tilde{x}_{2}+ & \cdots+ & a_{2 n} \tilde{x}_{n}=\tilde{y}_{2} \\
\vdots & \vdots & \vdots & \vdots \\
a_{m 1} \tilde{x}_{1}+ & a_{m 2} \tilde{x}_{2}+ & a_{m 3} \tilde{x}_{1}+ & a_{m n} \tilde{x}_{n}=\tilde{y}_{n}
\end{array}
$$

Dengan $a_{i j}$ adalah konstanta dan $\tilde{X}_{j}$ variabel yang belum diketahui dan dan $\tilde{y}_{j}$ adalah fuzzy. Persamaan (1) dan (2) dapat di tulis dalam bentuk persamaan matriks (3)

$$
A=\left[\begin{array}{cccc}
a_{11} & a_{12} & \cdots & a_{1 n} \\
a_{21} & a_{22} & \cdots & a_{2 n} \\
\vdots & \vdots & \vdots & \vdots \\
a_{m 1} & a_{m 2} & \cdots & a_{m n}
\end{array}\right] \quad \tilde{X}=\left[\begin{array}{c}
\tilde{x}_{1} \\
\tilde{x}_{2} \\
\tilde{x}_{3} \\
\vdots \\
\tilde{x}_{n}
\end{array}\right] \quad \tilde{Y}=\left[\begin{array}{c}
\tilde{y}_{1} \\
\tilde{y}_{2} \\
\tilde{y}_{3} \\
\vdots \\
\tilde{y}_{n}
\end{array}\right]
$$


Dengan matriks koefisien $A=a_{i j}$ untuk $i, j=1,2, \ldots, n, \tilde{x}$ adalah vektor bilangan fuzzy berukuran $n \times 1$ dengan $\tilde{x}_{i}=\underline{x}_{i}(r), \bar{x}_{i}(r), r=0,1$ dan $\tilde{y}_{i}=\underline{y}_{i}(r), \bar{y}_{i}(r)$, untuk $\mathrm{i}=1,2,3, \ldots \mathrm{n}$ adalah vektor bilangan bilangan fuzzy yang berukuran $\mathrm{n} x 1$.

Menurut Norita (2014) Langkah awal yang dilakukan untuk mencari solusi dari sistem persamaan linear fuzzy adalah mengubah matriks koefisien A yang berukuran $\mathrm{n} \times \mathrm{n}$ menjadi matriks yang berukuran $2 \mathrm{n} \times 2 \mathrm{n}$ yang diamsumsikan menjadi matriks $\mathrm{M}$

Ketentuan berikut:

1. Jika $a_{i, j} \geq 0$ maka $b_{i, j}=a_{i, j}$ dan $b_{i+n, j+n}=a_{i, j}$

2. Jika $a_{i, j}<0$ maka $b_{i, j+n}=-a_{i, j}$ dan $b_{i+n, j}=-a_{i, j}$

3. Entri yang lainnya $=0$

Definisi 1 Allahviranloo.T.(2004)

Vektor bilangan fuzzy $x_{1}, x_{2}, \ldots, x_{n}{ }^{T}$ dengan diberikan $\tilde{x}_{i}=\underline{x}_{i}(r), \bar{x}_{i}(r)$, untuk $\mathrm{i}=1,2, \ldots, \mathrm{n}$ dan $\mathrm{r}=0,1$ disubut penyelesaian dari sistem persamaan linear jika:

$$
\begin{aligned}
& \frac{\sum_{j=1}^{n} a_{i j} x_{j}}{\overline{\bar{n}}}=\sum_{\overline{j=1}}^{n} \underline{a_{i j} x_{j}}=\underline{y_{i}} \\
& \overline{\sum_{j=1}^{n} a_{i j} x_{j}}=\sum_{\overline{j=1}}^{n} \overline{a_{i j} x_{j}}=\overline{y_{i}}
\end{aligned}
$$

Menurut Matifar, Nasseri, dan Sharabi (2008) sistem persamaan linear fuzzy baru dapat dijelaskan:

$$
\begin{aligned}
& \begin{array}{cllclll}
S_{11} \underline{x}_{1}+ & \cdots+ & S_{1 n} \underline{x}_{n}+ & S_{1 n+1} \bar{x}_{2}+ & \cdots+ & S_{1,2 n} \bar{x}_{n} & = \\
\vdots & \vdots & \vdots & \underline{y}_{1} \\
S_{11} \underline{x}_{1}+ & \cdots+ & S_{n, n} \underline{x}_{n}+ & S_{n, n+1} \bar{x}_{2}+ & \cdots & \vdots & \vdots \\
& \cdots+ & S_{n, 2 n} \bar{x}_{n} & = & \underline{y}_{n}
\end{array}
\end{aligned}
$$

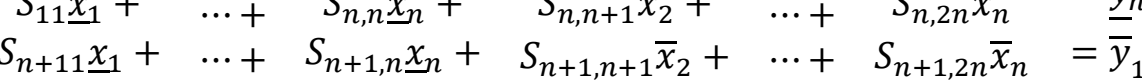

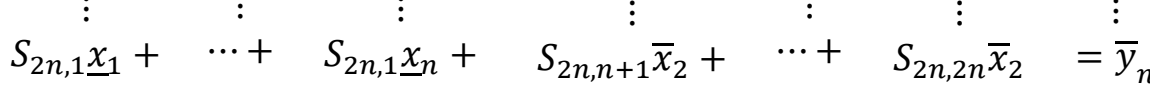

Persamaan 4.2 dapat ditulis:

$$
S \tilde{X}=\tilde{Y}
$$

Atau

$$
\left[\begin{array}{ll}
B_{1} & B_{2} \\
B_{2} & B_{1}
\end{array}\right]\left[\frac{X}{\bar{X}}\right]
$$

Dengan

$$
S=\left[\begin{array}{cc}
B_{1} & B_{2} \\
B_{2} & B_{1}
\end{array}\right], \underline{X}=\left[\begin{array}{c}
\underline{x}_{1}(r) \\
\vdots \\
\underline{x}_{n}(r)
\end{array}\right], \quad \bar{X}=\left[\begin{array}{c}
\bar{x}_{1}(r) \\
\vdots \\
\bar{x}_{n}(r)
\end{array}\right] \quad \underline{Y}=\left[\begin{array}{c}
\underline{y}_{1}(r) \\
\vdots \\
\underline{y}_{n}(r)
\end{array}\right] \quad \text { dan } \quad \underline{Y}=\left[\begin{array}{c}
\underline{y}_{1}(r) \\
\vdots \\
\underline{y}_{n}(r)
\end{array}\right]
$$

Definisi 2 Matinfar.M, dkk, (2008)

Terdapat $X=\underline{x}_{i}(r), \bar{x}_{i}(r), 1 \leq i \leq n$ adalah solusi dari $S X=Y$ dengan bilangan fuzzy $U=\underline{u}_{i}(r), \bar{u}_{i}(r), 1 \leq i \leq n$;

$\underline{u}(r)=\min \underline{x}_{i}(r), \bar{x}_{i}(r), \underline{x}_{i}(1), \bar{x}_{i}(1)$

$\bar{u}(r)=\max \underline{x}_{i}(r), \bar{x}_{i}(r), \underline{x}_{i}(1), \bar{x}_{i}(1)$

Solusi fuzzy $\widetilde{U}$ disebut solusi fuzzy kuat (strong fuzzy solution) jika $\underline{u}_{i}=\underline{x}_{i}, \bar{u}_{i}=\tilde{x}_{i}$, maka jika terdapat salah satu yang tidak sama maka $\widetilde{U}$ adalah solusi fuzzy lemah (weak fuzzy solution). 


\section{Metode Iterasi Jacobi}

Metode iterasi Jacobi ini digunakan untuk menyelesaikan persamaan linier yang proporsi koefisien nol nya besar. Metode ini ditemukan olek matematikawan yang berasal dari Jerman, Carl Gustav Jakob Jacobi. Penemuan ini diperkirakan pada tahun 1800-an. Iterasi dapat diartikan sebagai suatu proses atau metode yang digunakan secara berulang-ulang (pengulangan) dalam menyelesaikan suatu permasalahan matematika. Adapun metode iterasi Jacobi yaitu:

$$
x_{i}^{(k)}=\frac{1}{a_{i i}}\left(b_{i}-\sum_{j \neq i}^{n} a_{i j} x_{j}^{(k-1)}\right), i=1,2, \ldots, n ; k=1,2,3, \ldots, n
$$

\section{Metode Iterasi Gauss-Seidel}

Metode Gauss-Seidel digunakan untuk menyelesaikan sistem persamaan linier (SPL) berukuran besar dan proporsi koefisien nolnya besar, seperti sistem-sistem yang banyak ditemukan dalam sistem persamaan diferensial. Teknik iterasi jarang digunakan untuk menyelesaikan SPL berukuran kecil karena metode-metode langsung seperti metode eliminasi Gauss lebih efisien daripada metode iteratif. Akan tetapi, untuk SPL berukuran besar dengan persentase elemen nol pada matriks koefisien besar, teknik iterasi lebih efisien daripada metode langsung dalam hal penggunaan memori komputer maupun waktu komputasi. Metode iterasi Gauss-Seidel dapat dinyatakan sebagai berikut:

$$
x_{i}^{(k)}=\frac{1}{a_{i i}}\left(b_{i}-\sum_{j=1}^{i-1} a_{i j} x_{j}^{(k)}-\sum_{j=i+1}^{r} a_{i j} x_{j}^{(k-1)}\right)
$$

\section{Galat}

Misalkan $\bar{x}$ suatu nilai hampiran numerik untuk nilai numerik eksak $\mathrm{x}$, yang tidak diketahui. Nilai

$$
e_{\bar{x}}=x-\bar{x}
$$

\section{Himpunan Fuzzy (Fuzzy Set)}

Pada himpunan klasik, keberadaan suatu elemen $x$ dalam suatu himpunan A hanya memiliki dua kemungkinan keanggotaan, yaitu $x$ menjadi anggota $\mathrm{A}$ atau $x$ tidak menjadi anggota Suatu A nilai yang menunjukkan seberapa besar tingkat keanggotaan suatu elemen $x$ dalam suatu himpunan . biasa disebut dengan nilai keanggotaan, yang biasa ditulis dengan $\mu_{A}(x)$.

Ravita (2012) pada himpunan klasik, nilai keanggotaan hanya memasangkan nilai 0 atau 1 untuk unsur-unsur pada semesta pembicaraan, yang menyatakan anggota atau bukan anggota.

Nilai keanggotaan untuk himpunan A adalah fungsi $\mu_{A}: X \rightarrow\{0,1\}$.

\section{Bilangan Fuzzy}

$$
\mu_{A}(x)=\left\{\begin{array}{rr}
1, & \text { jika } x \in A \\
0, & \text { jika } x \notin A \text { atau } x \in A
\end{array}\right.
$$

Definisi 3 Kwang (2005)

Bilangan fuzzy u dalam $\mathrm{R}$ didefinisikan sebagai pasangan fungsi $(\underline{u}, \bar{u})$ yang memenuhi sifatsifat berikut:

1. Fungsi $\underline{u}$ monoton naik, terbatas, dan kontinu kiri pada $[0,1]$,

2. Fungsi $\bar{u}$ monoton turun, terbatas dan kontinu kanan pada [0,1], dan

3. $\underline{u}(\mathrm{r}) \leq \bar{u}(\mathrm{r})$ untuk setiap $\mathrm{r}$ dalam $[0,1]$, 
Himpunan bilangan-bilangan fuzzy dinyatakan dengan F. Untuk selanjutya, bilangan fuzzy u $\in$ $\mathrm{F}$ ditulis dalam bentuk parameter $\mathrm{u}=(\underline{u}, \bar{u})$.

Definisi 4 Allahviranloo (2005)

Operasi aljabar fuzzy menggunakan definisi yaitu untuk setiap $\mathrm{u}, \mathrm{v} \in \mathrm{F}$ dan bilangan real $\alpha$ didefinisikan :

a) $u=v$ jika dan hanya jika $\underline{u}=\underline{v}$ dan $\bar{u}=\bar{v}$.

b) $u+v=(\underline{u}+\underline{v}, \bar{u}+\bar{v})$

c) $\alpha u=(\alpha \underline{u}, \alpha \bar{u})$ untuk $\alpha \geq 0$

d) $\alpha u=(\alpha \bar{u}, \alpha \underline{u})$ untuk $\alpha \geq 0$

\section{METODE PENELITIAN}

Penelitian ini membandingkanmetode iterasi Jacobi dan Iterasi Gauss-Seidel untuk menyelesaikan sistem persamaan linear fuzzy. Dalam membandingkan kedua metode, yang diperhatikan adalah jumlah iterasi dan nilai errornya. Kedua hal ini akan digunakan untuk menentukan metode manakah yang lebih baik.

\section{HASIL DAN PEMBAHASAN}

Simulasi pertama

Diberikan contoh kasus persamaan

Penyelesaian solusi dari persamaan (8)

$$
\begin{aligned}
& \tilde{x}_{1}-\tilde{x}_{2}=-7+2 r,-3-2 r \\
& \tilde{x}_{1}-3 \tilde{x}_{2}=19+4 r, 27-4 r
\end{aligned}
$$

$$
\begin{gathered}
\left(\begin{array}{cc}
1 & -1 \\
1 & 3
\end{array}\right)\left(\begin{array}{l}
\tilde{x}_{1} \\
\tilde{x}_{2}
\end{array}\right)=\left(\begin{array}{ll}
-7+2 r & -3-2 r \\
19+4 r & 27-4 r
\end{array}\right) \\
A=\left(\begin{array}{cc}
1 & -1 \\
1 & 3
\end{array}\right) \tilde{x}=\left(\begin{array}{ll}
\underline{x}_{1}(r) & \bar{x}_{1}(r) \\
\underline{x}_{2}(r) & \bar{x}_{2}(r)
\end{array}\right) \\
\tilde{y}=\left(\begin{array}{cc}
-7+2 r & -3-2 r \\
19+4 r & 27-4 r
\end{array}\right)
\end{gathered}
$$

Sistem persamaan dari $\mathrm{n} \times \mathrm{n}$ diubah menjadi $2 \mathrm{n} \times 2 \mathrm{n}$ yang diamsumsikan dengan matriks $\mathrm{m}$

1. Jika $a_{i j} \geq 0$ maka $b_{i j}=a_{i j}, b_{i+n, j+n}=a_{i j}$

$$
\begin{array}{lll}
a_{11}=1 & b_{11}=1 & b_{33}=1 \\
a_{21}=1 & b_{21}=1 & b_{43}=1 \\
a_{22}=3 & b_{22}=3 & b_{44}=3
\end{array}
$$

2. Jika $a_{i j}<0$ maka $b_{i, j+n}=-a_{i j}$ dan $b_{i+n, j}=-a_{i j}$

$$
a_{12}=-1 \quad b_{14}=1 \quad b_{32}=1
$$

3. $b_{i j}$ bernilai nol untuk entri-entri yang lain.

Karena pada contoh diamsumsikan matriks m sehingga $b_{i j}=m_{i j}$. Berdasarkan entri-entri yang di dapat maka akan diperoleh persamaan (9) 


$$
\begin{gathered}
m_{11} \underline{x}_{1}+0 m_{12} \underline{x}_{2}+0 m_{13} \bar{x}_{1}+0 m_{13} \bar{x}_{1}=\underline{y}_{1} \\
m_{11} \underline{x}_{1}+3 m_{22} \underline{x}_{2}+0 m_{13} \bar{x}_{1}+0 m_{13} \bar{x}_{1}=\underline{y}_{2} \\
0 m_{31} \underline{x}_{1}+\quad m_{32} \underline{x}_{2}+0 m_{13} \bar{x}_{1}+0 m_{13} \bar{x}_{1}=\bar{y}_{1} \\
0 m_{41} \underline{x}_{1}+0 m_{42} \underline{x}_{2}+0 m_{13} \bar{x}_{1}+0 m_{13} \bar{x}_{1}=\bar{y}_{2}
\end{gathered}
$$

Persamaan dapat diubah menjadi bentuk persamaan matriks

$$
\left[\begin{array}{llll}
1 & 0 & 0 & 1 \\
1 & 3 & 0 & 0 \\
0 & 1 & 1 & 0 \\
0 & 0 & 1 & 3
\end{array}\right]\left[\begin{array}{l}
\underline{x}_{1} \\
\bar{x}_{2} \\
\bar{x}_{1} \\
\bar{x}_{2}
\end{array}\right]=\left[\begin{array}{c}
-7+2 r \\
19+4 r \\
-3-2 r \\
27-4 r
\end{array}\right]
$$

Dengan

$$
m=\left[\begin{array}{llll}
1 & 0 & 0 & 1 \\
1 & 3 & 0 & 0 \\
0 & 1 & 1 & 0 \\
0 & 0 & 1 & 3
\end{array}\right], \quad \tilde{x}=\left[\begin{array}{l}
\underline{x}_{1} \\
\underline{x}_{2} \\
\bar{x}_{1} \\
\bar{x}_{2}
\end{array}\right], \quad \tilde{y}=\left[\begin{array}{c}
-7+2 r \\
19+4 r \\
-3-2 r \\
27-4 r
\end{array}\right]
$$

Maka dengan melakukan operasi perkalian terhadap persamaan matriks diperoleh persamaan linear fuzzy

$$
\begin{aligned}
& \underline{x}_{1}+\bar{x}_{2}=-7+2 r \\
& \underline{x}_{1}+3 \underline{x}_{2} \quad=19+4 r \\
& \underline{x}_{2}+\bar{x}_{1}=-3-2 r \\
& \bar{x}_{1}+3 \bar{x}_{2}=27-4 r
\end{aligned}
$$

Penyelesaian sistem persamaan linear fuzzy yang baru ini dapat dilakukan dengan:

\section{Metode Iterasi Jacobi}

Berdasarkan persamaan (5)

$$
\begin{aligned}
x_{i}^{(k)}=\frac{1}{a_{i i}}\left(b_{i}-\sum_{j \neq i}^{n} a_{i j} x_{j}^{(k-1)}\right), & i=1,2, \ldots, n ; k=1,2,3, \ldots, n \\
\underline{x}_{1}{ }^{(k)} & =-\bar{x}_{2}{ }^{(k-1)}-7+2 r \\
\underline{x}_{2}{ }^{(k)} & =-\frac{1}{3} \underline{x}_{1}{ }^{(k-1)}+\frac{19+4 r}{3} \\
\bar{x}_{1}{ }^{(k)} & =-\underline{x}_{2}{ }^{(k-1)}-3-2 r \\
\bar{x}_{2}{ }^{(k)} & =-\frac{1}{3} \bar{x}_{1}{ }^{(k-1)}+\frac{27-4 r}{3}
\end{aligned}
$$

Iterasi Pertama

$$
\begin{aligned}
& \underline{x}_{1}^{(1)}=-\bar{x}_{2}^{(0)}-7+2 r \\
& \underline{x}_{2}^{(1)}=-\frac{1}{3} \underline{x}_{1}^{(0)}+\frac{19+4 r}{3} \\
& \bar{x}_{1}^{(1)}=-\frac{x_{2}^{(0)}-3-2 r}{1} \\
& x_{2}^{(1)}=-\frac{1}{3} \bar{x}_{1}^{(0)}+\frac{27-4 r}{3}
\end{aligned}
$$

Misalkan Nilai awal $\left(\underline{x}_{1}^{(0)}, \underline{x}_{2}^{(0)}, \bar{x}_{1}^{(0)}, \bar{x}_{2}^{(0)}=0\right)$ dengan mensubtitusi Nilai awal pada iterasi pertama maka di peroleh:

$$
\begin{aligned}
& \underline{x}_{1}^{(1)}=-7+2 r \\
& \underline{x}_{2}^{(1)}=\frac{19+4 r}{3}
\end{aligned}
$$




$$
\begin{aligned}
& \bar{x}_{1}^{(1)}=-3-2 r \\
& \bar{x}_{2}^{(1)}=\frac{27-4 r}{3}
\end{aligned}
$$

Untuk diperoleh iterasi kedua caranya adalah dengan mensubtitusi nilai

$$
\tilde{x}^{(1)}=\left[-7+2 r, \frac{19+4 r}{3},-3-2 r, \frac{27-4 r}{3}\right]
$$

Iterasi kedua

Dimana iterasi pertama :

$$
\begin{aligned}
& \underline{x}_{1}^{(2)}=-\bar{x}_{2}^{(1)}-7+2 r \\
& \underline{x}_{2}^{(2)}=-\frac{1}{3} \underline{x}_{1}^{(1)}+\frac{19+4 r}{3} \\
& \bar{x}_{1}^{(2)}=-\frac{x_{2}^{(1)}-3-2 r}{2} \\
& x_{2}^{(2)}=-\frac{1}{3} \bar{x}_{1}^{(1)}+\frac{27-4 r}{3}
\end{aligned}
$$

$$
\begin{gathered}
\tilde{x}^{(1)}=\left[-7+2 r, \frac{19+4 r}{3},-3-2 r, \frac{27-4 r}{3}\right] \\
\underline{x}_{1}^{(2)}=-\left(\frac{27-4 r}{3}\right)-7+2 r=\frac{-27-21+4 r+6 r}{3}=\frac{-48+10 r}{3} \\
\underline{x}_{2}^{(2)}=-\frac{1}{3}(-7+2 r)+\frac{19+4 r}{3}=\frac{(7+19)+(-2 r+4 r)}{3}=\frac{26+2 r}{3} \\
\bar{x}_{1}^{(2)}=-\left(\frac{19+4 r}{3}\right)-3-2 r=\frac{-19-9+(-4 r)-6 r}{3}=\frac{-28-10 r}{3} \\
\bar{x}_{2}^{(2)}=-\frac{1}{3}(-3-2 r)+\frac{27-4 r}{3}=\frac{3+27+2 r-4 r}{3}=\frac{30-2 r}{3} \\
\text { Jadi hasil iterasi ke dua adalah } \tilde{x}^{(2)}=\left[\frac{-48+10 r}{3}, \frac{26+2 r}{3}, \frac{-28-10 r}{3}, \frac{30-2 r}{3}\right]
\end{gathered}
$$

\section{Metode Iterasi Gauss - Seidel}

Berdasarkan persamaan (6)

$$
x_{i}^{(k)}=\frac{1}{a_{i i}}\left(b_{i}-\sum_{j=1}^{i-1} a_{i j} x_{j}^{(k)}-\sum_{j=i+1}^{r} a_{i j} x_{j}^{(k-1)}\right)
$$

Sehingga diperoleh:

$$
\begin{aligned}
& \underline{x}_{1}{ }^{(k)}=-\bar{x}_{2}{ }^{(k-1)}-7+2 r \\
& \underline{x}_{2}{ }^{(k)}=-\frac{1}{3} \underline{x}_{1}{ }^{(k)}+\frac{19+4 r}{3} \\
& \bar{x}_{1}{ }^{(k)}=-\frac{x_{2}}{}{ }^{(k)}-3-2 r \\
& \bar{x}_{2}{ }^{(k)}=-\frac{1}{3} \bar{x}_{1}{ }^{(k)}+\frac{27-4 r}{3}
\end{aligned}
$$

Iterasi pertama

$$
\begin{aligned}
& \underline{x}_{1}{ }^{(1)}=-\bar{x}_{2}{ }^{(0)}-7+2 r \\
& \underline{x}_{2}{ }^{(1)}=-\frac{1}{3} \underline{x}_{1}{ }^{(1)}+\frac{19+4 r}{3} \\
& \bar{x}_{1}{ }^{(1)}=-\underline{x}_{2}{ }^{(1)}-3-2 r \\
& \bar{x}_{2}{ }^{(1)}=-\frac{1}{3} \bar{x}^{(1)}+\frac{27-4 r}{3}
\end{aligned}
$$


Misalkan Nilai awal $\left(\underline{x}_{1}^{(0)}, \underline{x}_{2}^{(0)}, \bar{x}_{1}^{(0)}, \bar{x}_{2}^{(0)}=0\right)$ dengan mensubtitusi Nilai awal pada iterasi pertama maka di peroleh:

$$
\begin{aligned}
& \underline{x}_{1}^{(1)}=-\bar{x}_{2}{ }^{(0)}-7+2 r=0-7+2 r=-7+2 r \\
& \underline{x}_{2}^{(1)}=-\frac{1}{3} \underline{x}_{1}^{(1)}+\frac{19+4 r}{3}=-\frac{1}{3}(-7+2 r)+\frac{19+4 r}{3}=\frac{7+19-2 r+4 r}{3}=\frac{26+2 r}{3} \\
& \bar{x}_{1}^{(1)}=-\underline{x}_{2}^{(1)}-3-2 r=-\left(\frac{26+2 r}{3}\right)-3-2 r=\frac{-26-9-2 r-6 r}{3}=\frac{-35-8 r}{3} \\
& \bar{x}_{2}^{(1)}=-\frac{1}{3} \bar{x}_{1}^{(1)}+\frac{27-4 r}{3}=-\frac{1}{3}\left(\frac{-35-8 r}{3}\right)+\frac{27-4 r}{3}=\frac{35+81+8 r-12 r}{9} \\
& =\frac{116-4 r}{9}
\end{aligned}
$$

jadi iterasi pertama: $\tilde{x}^{(1)}=\left[-7+2 r, \frac{26+2 r}{3}, \frac{-35-8 r}{3}, \frac{116-4 r}{9}\right]$.

Iterasi kedua:

Dimana iterasi pertama diperoleh:

$$
\begin{aligned}
& \underline{x}_{1}{ }^{(2)}=-\bar{x}_{2}{ }^{(1)}-7+2 r \\
& \underline{x}_{2}{ }^{(2)}=-\frac{1}{3} \underline{x}_{1}{ }^{(2)}+\frac{19+4 r}{3} \\
& \bar{x}_{1}{ }^{(2)}=-\underline{x}_{2}{ }^{(2)}-3-2 r \\
& \bar{x}_{2}{ }^{(2)}=-\frac{1}{3} \bar{x}_{1}{ }^{(2)}+\frac{27-4 r}{3}
\end{aligned}
$$

Maka diperoleh:

$$
\tilde{x}^{(1)}=\left[-7+2 r, \frac{26+2 r}{3}, \frac{-35-8 r}{3}, \frac{116-4 r}{9}\right]
$$

$$
\begin{aligned}
& \underline{x}_{1}^{(2)}=-\bar{x}_{2}{ }^{(1)}-7+2 r=-\left(\frac{116-4 r}{9}\right)-7+2 r=\frac{-116-63+4 r+18 r}{9} \\
& =\frac{-179+22 r}{9} \\
& \underline{x}_{2}{ }^{(2)}=-\frac{1}{3} \underline{x}_{1}^{(2)}+\frac{19+4 r}{3}=-\frac{1}{3}\left(\frac{-179+22 r}{9}\right)+\frac{19+4 r}{3}=\frac{179+171-22 r+36 r}{27} \\
& =\frac{350+14 r}{27} \\
& \bar{x}_{1}{ }^{(2)}=-\underline{x}_{2}{ }^{(2)}-3-2 r=-\left(\frac{350+14 r}{27}\right)-3-2 r=\frac{-350-81-14 r-54 r}{27} \\
& =\frac{-431-68 r}{27} \\
& \bar{x}_{2}{ }^{(2)}=-\frac{1}{3} \bar{x}_{1}{ }^{(2)}+\frac{27-4 r}{3}=-\frac{1}{3}\left(\frac{-431-68 r}{27}\right)+\frac{27-4 r}{3}=\frac{431+729+68 r-108 r}{81} \\
& =\frac{1160-40 r}{81}
\end{aligned}
$$

Jadi hasil Iterasi kedua yaitu : $\tilde{x}^{(2)}=\left[\frac{-179+22 r}{9}, \frac{350+14 r}{27}, \frac{-431-68 r}{27}, \frac{1160-40 r}{81}\right]$

Dari hasil simulasi pertama berdasarkan lampiran 1 dan lampiran 2 dengan syarat pemberhentian iterasi $\left|x_{n}-x_{n-1}\right|<\varepsilon\left(\varepsilon=10^{-4}\right)$ diperoleh:

1. Metode Iterasi Jacobi mendapatkan Iterasi pemberhentian pada iterasi ke 22 dan metode Iterasi Gauss-Seidel mendapatkan Iterasi pemberhentian pada iterasi Ke 8 dan

2. Error pada metode Gauss-Seidel lebih cepat konvergen dari pada metode jacobi. Hal ini menunjukkan bahwa metode Iterasi Gauss-Seidel lebih baik digunakan ketimbang metode iterasi Jacobi. 


\section{Simulasi kedua}

Sebuah sirkuit Listrik dalam Penerapan Sistem persamaan Linear Fuzzy untuk menganalisis sirkuit tersebut dengan sumber yang sama dengan arus sebagai Fuzzy dan resistensinya yang terlihat pada gambar berikut:

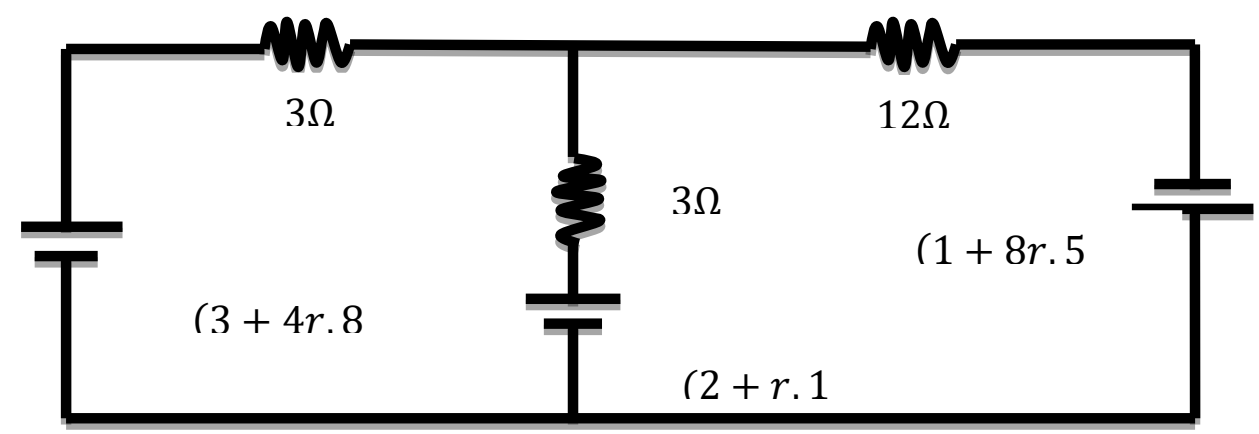

GAMBAR 1.Sirkuit arus Listrik

Berdasarkan hukum kirchoff 2:

Keterangan:

$$
\sum \varepsilon+\sum I \cdot R=0
$$

$\varepsilon \quad=$ jumlah ggl Sumber arus $(\mathrm{V})$

I.R = Jumlah Penurunan tegangan $(\mathrm{V})$

I $\quad=$ arus Listrik (A)

$\mathrm{R} \quad=$ hambatan $(\mathrm{W})$

Maka diperoleh berdasarkan hukum kirchoff 2 pada Gambar 2 yaitu:

$3 I_{1}+3\left(I_{1}-I_{2}\right)=(3+4 r, 8+11 r)-(2+r, 1+r)$

$3\left(I_{1}-I_{2}\right)+12 I_{2}=(3+4 r, 8+11 r)-(2+r, 1+r)$

Maka hasil operasi dari persamaan (10) dan (11) menjadi

$$
\begin{aligned}
& 6 I_{1}+3 I_{2}=(1+3 r, 7+10 r) \\
& I_{1}+3 I_{2}=(1+3 r, 2-6 r)
\end{aligned}
$$

Misalkan

$I_{1}=\tilde{x}_{1}$

$I_{2}=\tilde{x}_{2}$

Maka diperoleh :

$$
\begin{aligned}
& 6 \tilde{x}_{1}-3 \tilde{x}_{2}=1+3 r, 7+10 r \\
& \tilde{x}_{1}+3 \tilde{x}_{2}=1+3 r, 2-6 r
\end{aligned}
$$

Penyelesaian solusi dari persamaan (12)

$$
\begin{gathered}
A \tilde{x}=\tilde{y} \\
\left(\begin{array}{cc}
6 & -3 \\
1 & 3
\end{array}\right)\left(\begin{array}{l}
\tilde{x}_{1} \\
\tilde{x}_{2}
\end{array}\right)=\left(\begin{array}{ll}
1+3 r & 7+10 r \\
1+3 r & 2-6 r
\end{array}\right) \\
A=\left(\begin{array}{cc}
6 & -3 \\
1 & 3
\end{array}\right) \tilde{x}=\left(\begin{array}{ll}
\underline{x}_{1}(r) & \bar{x}_{1}(r) \\
\underline{x}_{2}(r) & \bar{x}_{2}(r)
\end{array}\right) \\
\tilde{y}=\left(\begin{array}{ll}
1+3 r & 7+10 r \\
1+3 r & 2-6 r
\end{array}\right)
\end{gathered}
$$

Sistem persamaan dari $\mathrm{n} \times \mathrm{n}$ diubah menjadi $2 \mathrm{n} \times 2 \mathrm{n}$ yang diamsumsikan dengan matriks $\mathrm{m}$

1. Jika $a_{i j} \geq 0$ maka $b_{i j}=a_{i j}, b_{i+n, j+n}=a_{i j}$

$$
\begin{array}{lll}
a_{11}=6 & b_{11}=6 & b_{33}=6 \\
a_{21}=1 & b_{21}=1 & b_{43}=1 \\
a_{22}=3 & b_{22}=3 & b_{44}=3
\end{array}
$$


2. Jika $a_{i j}<0$ maka $b_{i, j+n}=-a_{i j}$ dan $b_{i+n, j}=-a_{i j}$

$$
a_{12}=-3 \quad b_{14}=3 \quad b_{32}=3
$$

3. $b_{i j}$ bernilai nol untuk entri-entri yang lain.

Karena pada contoh diamsumsikan matriks m sehingga $b_{i j}=m_{i j}$. Berdasarkan entri-entri yang di dapat maka akan diperoleh persamaan (13)

$$
\begin{gathered}
6 m_{11} \underline{x}_{1}+0 m_{12} \underline{x}_{2}+0 m_{13} \bar{x}_{1}+3 m_{13} \bar{x}_{1}=\underline{y}_{1} \\
m_{11} \underline{x}_{1}+3 m_{22} \underline{x}_{2}+0 m_{13} \bar{x}_{1}+0 m_{13} \bar{x}_{1}=\underline{y}_{2} \\
0 m_{31} \underline{x}_{1}+3 m_{32} \underline{x}_{2}+6 m_{13} \bar{x}_{1}+0 m_{13} \bar{x}_{1}=\bar{y}_{1} \\
0 m_{41} \underline{x}_{1}+0 m_{42} \underline{x}_{2}+m_{13} \bar{x}_{1}+3 m_{13} \bar{x}_{1}=\bar{y}_{2}
\end{gathered}
$$

Persamaan diatas dapat diubah menjadi bentuk persamaan matriks baru (14)

$$
\left(\begin{array}{llll}
6 & 0 & 0 & 3 \\
1 & 3 & 0 & 0 \\
0 & 3 & 6 & 0 \\
0 & 0 & 1 & 3
\end{array}\right)\left(\begin{array}{c}
\underline{x}_{1} \\
\bar{x}_{2} \\
\bar{x}_{1} \\
\bar{x}_{2}
\end{array}\right)=\begin{gathered}
1+3 r \\
1+3 r \\
7+10 r \\
2-6 r
\end{gathered}
$$

Dengan

$$
m=\left(\begin{array}{llll}
6 & 0 & 0 & 3 \\
1 & 3 & 0 & 0 \\
0 & 3 & 6 & 0 \\
0 & 0 & 1 & 3
\end{array}\right), \quad \tilde{x}=\left(\begin{array}{c}
\underline{x}_{1} \\
\underline{x}_{2} \\
\bar{x}_{1} \\
\bar{x}_{2}
\end{array}\right), \quad \begin{array}{r}
1+3 r \\
1+3 r \\
7+10 r \\
2-6 r
\end{array}
$$

Maka dengan melakukan operasi perkalian terhadap persamaan matriks diperoleh persamaan linear fuzzy:

$$
\begin{array}{rrrrr}
\underline{6 x}_{1} & & +3 \bar{x}_{2} & =1+3 r \\
\underline{x}_{1}+3 \underline{x}_{2} & & & =1+3 r \\
& \underline{3 x}_{2}+6 \bar{x}_{1} & & =7+10 r \\
& & \bar{x}_{1}+3 \bar{x}_{2} & =2-6 r
\end{array}
$$

Penyelesaian sistem persamaan linear fuzzy yang baru ini dapat dilakukan dengan

\section{Metode Iterasi Jacobi}

Berdasarkan persamaan (6)

$x_{i}^{(k)}=\frac{1}{a_{i i}}\left(b_{i}-\sum_{j \neq i}^{n} a_{i j} x_{j}^{(k-1)}\right), i=1,2, \ldots, n ; k=1,2,3, \ldots, n$

Sehingga diperoleh:

Iterasi pertama

$$
\begin{aligned}
& \underline{x}_{1}^{(k)}=-\frac{1}{2} \bar{x}_{2}^{(k-1)}+\frac{1+3 r}{6} \\
& \underline{x}_{2}^{(k)}=-\frac{1}{3} \underline{x}_{1}^{(k-1)}+\frac{1+3 r}{3} \\
& \bar{x}_{1}^{(k)}=-\frac{1}{2} \underline{x}_{2}^{(k-1)}+\frac{7+10 r}{6} \\
& \bar{x}_{2}^{(k)}=-\frac{1}{3} \bar{x}_{1}^{(k-1)}+\frac{2-6 r}{3}
\end{aligned}
$$

$$
\underline{x}_{1}^{(1)}=-\frac{1}{2} \bar{x}_{2}^{(0)}+\frac{1+3 r}{6}
$$




$$
\begin{aligned}
& \underline{x}_{2}^{(1)}=-\frac{1}{3} \underline{x}_{1}^{(0)}+\frac{1+3 r}{3} \\
& \bar{x}_{1}^{(1)}=-\frac{1}{2} \underline{x}_{2}^{(0)}+\frac{7+10 r}{6} \\
& \bar{x}_{2}^{(1)}=-\frac{1}{3} \bar{x}_{1}{ }^{(0)}+\frac{2-6 r}{3}
\end{aligned}
$$

Misalkan Nilai awal $\left(\underline{x}_{1}^{(0)}, \underline{x}_{2}^{(0)}, \bar{x}_{1}^{(0)}, \bar{x}_{2}^{(0)}=0\right)$ dengan mensubtitusi Nilai awal pada iterasi pertama maka di peroleh:

$$
\begin{aligned}
& \underline{x}_{1}^{(1)}=-\frac{1}{2}(0)+\frac{1+3 r}{6}=\frac{1+3 r}{6} \\
& \underline{x}_{2}^{(1)}=-\frac{1}{3}(0)+\frac{1+3 r}{3}=\frac{1+3 r}{3} \\
& \bar{x}_{1}^{(1)}=-\frac{1}{2}(0)+\frac{7+10 r}{6}=\frac{7+10 r}{6} \\
& \bar{x}_{2}^{(1)}=-\frac{1}{3}(0)+\frac{2-6 r}{3}=\frac{2-6 r}{3}
\end{aligned}
$$

Jadi hasil iterasi pertama diperoleh: $\left[\frac{1+3 r}{6}, \frac{1+3 r}{3}, \frac{7+10 r}{6}, \frac{2-6 r}{3}\right]$

Iterasi kedua

dimana iterasi pertama diperoleh: $\left[\frac{1+3 r}{6}, \frac{1+3 r}{3}, \frac{7+10 r}{6}, \frac{2-6 r}{3}\right]$

$$
\begin{aligned}
& \underline{x}_{1}^{(2)}=-\frac{1}{2} \bar{x}_{2}^{(1)}+\frac{1+3 r}{6} \\
& \underline{x}_{2}^{(2)}=-\frac{1}{3} \underline{x}_{1}^{(1)}+\frac{1+3 r}{3} \\
& \bar{x}_{1}^{(2)}=-\frac{1}{2} \underline{x}_{2}^{(1)}+\frac{7+10 r}{6} \\
& \bar{x}_{2}^{(2)}=-\frac{1}{3} \bar{x}_{1}^{(1)}+\frac{2-6 r}{3}
\end{aligned}
$$

$$
\begin{gathered}
\underline{x}_{1}^{(2)}=-\frac{1}{2}\left(\frac{2-6 r}{3}\right)+\frac{1+3 r}{6}=\frac{-2+1+6 r+3 r}{6}=\frac{-1+9 r}{6} \\
\underline{x}_{2}^{(2)}=-\frac{1}{3}\left(\frac{1+3 r}{6}\right)+\frac{1+3 r}{3}=\frac{5+15 r}{18} \\
\bar{x}_{1}^{(2)}=-\frac{1}{2}\left(\frac{1+3 r}{3}\right)+\frac{7+10 r}{6}=\frac{6+7 r}{6} \\
\bar{x}_{2}^{(2)}=-\frac{1}{3}\left(\frac{7+10 r}{6}\right)+\frac{2-6 r}{3}=\frac{5-46 r}{18}
\end{gathered}
$$

Jadi iterasi kedua: $\left[\frac{-1+9 r}{6}, \frac{5+15 r}{18}, \frac{6+7 r}{6}, \frac{5-46 r}{18}\right]$

\section{Metode Iterasi Gauss - Seidel}

Berdasarkan persamaan (7)

$$
x_{i}^{(k)}=\frac{1}{a_{i i}}\left(b_{i}-\sum_{j=1}^{i-1} a_{i j} x_{j}^{(k)}-\sum_{j=i+1}^{r} a_{i j} x_{j}^{(k-1)}\right)
$$

Sehingga diperoleh dari contoh 2 yaitu:

$$
\begin{aligned}
& \underline{x}_{1}^{(k)}=-\frac{1}{2} \bar{x}_{2}^{(k-1)}+\frac{1+3 r}{6} \\
& \underline{x}_{2}^{(k)}=-\frac{1}{3} \underline{x}_{1}^{(k)}+\frac{1+3 r}{3} \\
& \bar{x}_{1}^{(k)}=-\frac{1}{2} \underline{x}_{2}^{(k)}+\frac{7+10 r}{6}
\end{aligned}
$$




$$
\bar{x}_{2}^{(k)}=-\frac{1}{3} \bar{x}_{1}^{(k)}+\frac{2-6 r}{3}
$$

Iterasi pertama

$$
\begin{aligned}
& \underline{x}_{1}^{(1)}=-\frac{1}{2} \bar{x}_{2}^{(0)}+\frac{1+3 r}{6} \\
& \underline{x}_{2}^{(1)}=-\frac{1}{3} \underline{x}_{1}^{(1)}+\frac{1+3 r}{3} \\
& \bar{x}_{1}^{(1)}=-\frac{1}{2} \underline{x}_{2}^{(1)}+\frac{7+10 r}{6} \\
& \bar{x}_{2}^{(1)}=-\frac{1}{3} \bar{x}_{1}^{(1)}+\frac{2-6 r}{3}
\end{aligned}
$$

Misalkan Nilai awal $\left(\underline{x}_{1}^{(0)}, \underline{x}_{2}^{(0)}, \bar{x}_{1}^{(0)}, \bar{x}_{2}^{(0)}=0\right)$ dengan mensubtitusi Nilai awal pada iterasi pertama maka di peroleh:

$$
\begin{aligned}
& \underline{x}_{1}^{(1)}=-\frac{1}{2}(0)+\frac{1+3 r}{6}=\frac{1+3 r}{6} \\
& \underline{x}_{2}^{(1)}=-\frac{1}{3}\left(\frac{1+3 r}{6}\right)+\frac{1+3 r}{3}=\frac{-1+6-3 r+18 r}{18}=\frac{5+15 r}{18} \\
& \bar{x}_{1}^{(1)}=-\frac{1}{2}\left(\frac{5+15 r}{18}\right)+\frac{7+10 r}{6}=\frac{-5+42-15 r+60 r}{36}=\frac{37+45 r}{36} \\
& \bar{x}_{2}^{(1)}=-\frac{1}{3}\left(\frac{37+45 r}{36}\right)+\frac{2-6 r}{3}=\frac{35-261 r}{108}
\end{aligned}
$$

Jadi hasil iterasi pertama yaitu: $\left[\frac{1+3 r}{6}, \frac{5+15 r}{18}, \frac{37+45 r}{36}, \frac{35-261 r}{108}\right]$

Iterasi kedua

$$
\begin{aligned}
& \underline{x}_{1}^{(2)}=-\frac{1}{2} \bar{x}_{2}^{(1)}+\frac{1+3 r}{6} \\
& \underline{x}_{2}^{(2)}=-\frac{1}{3} \underline{x}_{1}^{(2)}+\frac{1+3 r}{3} \\
& \bar{x}_{1}^{(2)}=-\frac{1}{2} \underline{x}_{2}^{(2)}+\frac{7+10 r}{6} \\
& \bar{x}_{2}^{(2)}=-\frac{1}{3} \bar{x}_{1}^{(2)}+\frac{2-6 r}{3}
\end{aligned}
$$

Dimana iterasi pertama yaitu: $\left[\frac{1+3 r}{6}, \frac{5+15 r}{18}, \frac{37+45 r}{36}, \frac{35-261 r}{108}\right]$

$\underline{x}_{1}^{(2)}=-\frac{1}{2}\left(\frac{35-261 r}{108}\right)+\frac{1+3 r}{6}=\frac{-35+36+261 r+108 r}{216}=\frac{1+369 r}{216}$

$\underline{x}_{2}^{(2)}=-\frac{1}{3}\left(\frac{1+369 r}{216}\right)+\frac{1+3 r}{3}=\frac{-1+216-369 r+648 r}{648}=\frac{215+279 r}{648}$

$\bar{x}_{1}^{(2)}=-\frac{1}{2}\left(\frac{215+279 r}{648}\right)+\frac{7+10 r}{6}=\frac{-215+1512-279 r+2160 r}{1296}=\frac{1297+1881 r}{1296}$

$\bar{x}_{2}^{(2)}=-\frac{1}{3}\left(\frac{1297+1881 r}{1296}\right)+\frac{2-6 r}{3}=\frac{-1297+2592-1888 r-7776 r}{3888}=\frac{1295-9657 r}{3888}$

Jadi hasil iterasi kedua yaitu: $\left[\frac{1+369 r}{216}, \frac{215+279 r}{648}, \frac{1297+1881 r}{1296}, \frac{1295-9657 r}{3888}\right]$

Dari hasil simulasi kedua berdasarkan lampiran 3 dan lampiran 4 dengan syarat pemberhentian iterasi $\left|x_{n}-x_{n-1}\right|<\varepsilon\left(\varepsilon=10^{-4}\right)$ bahwa

1. Metode Iterasi Jacobi mendapatkan Iterasi pemberhentian pada iterasi ke 11 dan metode Iterasi Gauss-Seidel mendapatkan Iterasi pemberhentian pada iterasi Ke 4 dan

2. Error pada metode Gauss-Seidel lebih cepat konvergen dari pada metode Jacobi Hal ini menunjukkan bahwa metode Iterasi Gauss-Seidel lebih baik digunakan ketimbang metode iterasi Jacobi. 


\section{KESIMPULAN}

Hasil simulasi pertama berdasarkan lampiran 1 dan lampiran 2 dengan syarat pemberhentian iterasi pada persamaan (7) diperoleh:

1. Metode Iterasi Jacobi mendapatkan Iterasi pemberhentian pada iterasi ke 22 sedangkan metode Iterasi Gauss-Seidel mendapatkan Iterasi pemberhentian pada iterasi Ke 8.

2. Nilai error pada metode Gauss-Seidel lebih cepat konvergen dari pada metode Jacobi.

Hal ini menunjukkan bahwa metode Iterasi Gauss-Seidel lebih baik digunakan ketimbang metode iterasi Jacobi pada kasus simulasi pertama.

Dari hasil simulasi kedua berdasarkan lampiran 3 dan lampiran 4 dengan syarat pemberhentian iterasi pada persamaan (7) diperoleh:

1. Metode Iterasi Jacobi mendapatkan Iterasi pemberhentian pada iterasi ke 11 sedangkan metode Iterasi Gauss-Seidel mendapatkan Iterasi pemberhentian pada iterasi Ke 4

2. Nilai error pada metode Gauss-Seidel lebih cepat konvergen dari pada metode Jacobi.

Hal ini menunjukkan bahwa metode Iterasi Gauss-Seidel lebih baik digunakan ketimbang metode iterasi Jacobi pada kasus simulasi kedua.

Niyyaka (2016) menyatakan bahwa Metode Iterasi Gauss-Seidel lebih baik dibandingkan Metode Iterasi Jacobi dalam menyelesaikan sistem persamaan linear dengan menggunakan simulasi komputer. Dalampenelitian yang diperoleh pada kasus sistem persamaan linear fuzzy bahwa Iterasi Gauss-Seidel lebih baik dibandingkan Iterasi Jacobi, hal inimenunjukkan bahwa penelitian tersebut sejalan dengan penelitian yang dilakukan oleh Niyyaka (2016) meskipun berbeda konteks penyelesaian persamaan.

Penelitian ini membandingkan dua metode numerik yaitu metode iterasi Jacobi dan Metode iterasi Gauss-seidel. Peneliti menyarankan bagi peneliti selanjutnya meneliti dengan metode numerik lain seperti Metode Secant, Metode Dekomposisi dan Metode Bagi dua. Selain itu, dapat pula digunakan Persamaan fuzzy berbeda seperti: Persamaan Non-Linear Fuzzy dan Persamaan Linear Fuzzy Complex.

\section{DAFTAR PUSTAKA}

Abdi, M. (2008). Dasar-dasar Teori Himpunan Kabur dan Logika Kabur. Makassar: Badan Penerbit UNM.

Anton, H. (1997). Aljabar Linear Elementer. Jakarta: Erlangga.

Kholifah.(2013). Penyelesaian Persamaan Linear Fully Fuzzy Menggunakan Metode GaussSeidel. (Skripsi tidak dipublikasikan)Universitas Islam Negeri Sultan Syarif Kasim Riau.

Kusumadewi, S., \&Purnomo. H. (2010). Aplikasi Logika Fuzzy untuk Pendukung Keputusan, edisi Kedua. Yogyakarta: Graha Ilmu.

Kwang, F, L, (2005).First course on Fuzzy Theory and Aplications. Germany :Springer.

Matinfar. M., Nasseri \&Sharabi.(2008).Solving Fuzzy Linear System of Equations by Using Haouseholder Decomposition Method.Applied Mathematical Sciences,2.(52).25692575.

Niyyaka, (2016). Perbandingan Metode Iterasi Jacobi dan Iterasi Gauss-Seidel Dalam Penyelesaian Sistem Persamaan Linear dengan Menggunakan Simulasi Komputer. (Skripsi,tidak dipublikasikan) Universitas Negeri Lampung.

Norita. B. (2014). Sistem Persamaan Linear fuzzy .Jurnal Matematika FMIPA Universitas Diponegoro Semarang. Vol (3).1-8. 
Ravita. E, \& Evawati. A. (2012). Studi Tentang Persamaan Fuzzy.Jurnal Matematika. 20860382 :

Sahid. (2005). Pengantar Komputasi Numerik dengan Matlab. Yogyakarta : Andi.

Sivanandam, S.N., Sumanthi, S., \& Deepa, S.N., (2007).Introduction to Fuzzy Logic using Matlab. Berlin : Springer.

Allahviranloo,T. (2004).Numerical methods for fuzzy system of linear equatons. .Iran:Appl.Math.Comput.

Allahviranloo, T. (2005), The Adomian decomposition method for fuzzy system of linear equations. Iran :Appl Math Comput.

Wibowo,(2012). Penyelesaian Sistem Persamaan Fuzzy Non-Linear dengan Menggunakan Metode Broyden. (Skripsi,tidak dipublikasikan). Universitas Islam Negeri Maulana Malik Ibrahim. 
IMED 2(1) 2019, hal. 1 - 18

LAMPIRAN 1. Simulasi Pertama dengan Metode Iterasi Jacobi

\begin{tabular}{|c|c|c|c|c|c|c|c|c|c|c|}
\hline \multirow[t]{2}{*}{$\begin{array}{c}\text { r/iterasi } \\
\text { ke n }\end{array}$} & \multicolumn{5}{|c|}{$\mathbf{r}=\mathbf{0}$} & \multicolumn{5}{|c|}{$r=0.1$} \\
\hline & $x_{1}$ & $x_{2}$ & $x_{3}$ & $x_{4}$ & error & $x_{1}$ & $x_{2}$ & $x_{3}$ & $x_{4}$ & error \\
\hline 1 & -7.0000 & 6.3333 & -3.0000 & 9.0000 & 13.3832 & -6.8000 & 6.4667 & -3.2000 & 8.8667 & 13.301 \\
\hline$\vdots$ & $\vdots$ & $\vdots$ & $\vdots$ & $\vdots$ & $\vdots$ & $\vdots$ & $\vdots$ & $\vdots$ & $\vdots$ & $\vdots$ \\
\hline 22 & $\begin{array}{c}- \\
21.4999\end{array}$ & 13.4999 & $\begin{array}{c}- \\
16.4999\end{array}$ & 14.4999 & 0.00019127 & $\begin{array}{c}- \\
21.2499\end{array}$ & 13.5499 & $\begin{array}{c}- \\
16.7499\end{array}$ & 14.4499 & 0.00019063 \\
\hline \multirow[t]{2}{*}{$\begin{array}{l}\text { r/iterasi } \\
\text { ke n }\end{array}$} & \multicolumn{5}{|c|}{$\mathbf{r}=0.2$} & \multicolumn{5}{|c|}{$r=0.3$} \\
\hline & $\frac{\boldsymbol{x}_{\mathbf{1}}}{-6.6000}$ & $\frac{x_{2}}{6.6000}$ & $\begin{array}{c}\boldsymbol{x}_{\mathbf{3}} \\
-3.4000\end{array}$ & $\begin{array}{c}\boldsymbol{x}_{\mathbf{4}} \\
8.7333\end{array}$ & $\begin{array}{c}\text { error } \\
13.2269\end{array}$ & $\frac{\boldsymbol{x}_{\mathbf{1}}}{-6.4000}$ & $\frac{x_{\mathbf{2}}}{6.7333}$ & $\begin{array}{c}\boldsymbol{x}_{\mathbf{3}} \\
-3.6000\end{array}$ & $\begin{array}{c}\boldsymbol{x}_{\mathbf{4}} \\
8.6000\end{array}$ & $\begin{array}{c}\text { error } \\
13.1612\end{array}$ \\
\hline$\vdots$ & $\vdots$ & $\vdots$ & $\vdots$ & $\vdots$ & $\vdots$ & $\vdots$ & $\vdots$ & $\vdots$ & $\vdots$ & $\vdots$ \\
\hline 22 & $\begin{array}{c}- \\
20.9999 \\
\end{array}$ & 13.5999 & $\begin{array}{c}- \\
16.9999 \\
\end{array}$ & 14.3999 & 0.00019006 & $\begin{array}{c}- \\
20.7499\end{array}$ & 13.6499 & $\begin{array}{c}- \\
17.2499\end{array}$ & 14.3499 & 0.00018956 \\
\hline \multirow[t]{2}{*}{$\begin{array}{c}\text { r/iterasi } \\
\text { ke n }\end{array}$} & \multicolumn{5}{|c|}{$r=0.4$} & \multicolumn{5}{|c|}{$\mathbf{r}=0.5$} \\
\hline & $\frac{\boldsymbol{x}_{\mathbf{1}}}{-6.2000}$ & $\begin{array}{c}\boldsymbol{x}_{\mathbf{2}} \\
6.8667\end{array}$ & $\frac{\boldsymbol{x}_{\mathbf{3}}}{-3.8000}$ & $\begin{array}{c}\boldsymbol{x}_{\mathbf{4}} \\
8.4667\end{array}$ & $\begin{array}{c}\text { error } \\
13.104\end{array}$ & $\frac{\boldsymbol{x}_{\mathbf{1}}}{-6.0000}$ & $\frac{\boldsymbol{x}_{\mathbf{2}}}{7.0000}$ & $\frac{\boldsymbol{x}_{\mathbf{3}}}{-4.0000}$ & $\frac{\boldsymbol{x}_{\mathbf{4}}}{8.3333}$ & $\begin{array}{c}\text { error } \\
13.0554\end{array}$ \\
\hline$\vdots$ & $\vdots$ & $\vdots$ & $\vdots$ & $\vdots$ & $\vdots$ & $\vdots$ & $\vdots$ & $\vdots$ & $\vdots$ & $\vdots$ \\
\hline 22 & $\begin{array}{c}- \\
20.4999 \\
\end{array}$ & 13.6999 & $\begin{array}{c}- \\
17.4999\end{array}$ & 14.2999 & 0.00018912 & $\begin{array}{c}- \\
20.2499\end{array}$ & 13.7499 & $\begin{array}{c}- \\
17.7499\end{array}$ & 14.2499 & 0.00018875 \\
\hline \multirow[t]{2}{*}{$\begin{array}{c}\text { r/iterasi } \\
\text { ke n }\end{array}$} & \multicolumn{5}{|c|}{$r=0.6$} & \multicolumn{5}{|c|}{$\mathbf{r}=0.7$} \\
\hline & $\begin{array}{c}\boldsymbol{x}_{\mathbf{1}} \\
-5.8000\end{array}$ & $\begin{array}{c}\boldsymbol{x}_{\mathbf{2}} \\
7.1333 \\
\end{array}$ & $\begin{array}{c}\boldsymbol{x}_{\mathbf{3}} \\
-4.2000\end{array}$ & $\begin{array}{c}\boldsymbol{x}_{\mathbf{4}} \\
8.2000\end{array}$ & $\begin{array}{c}\text { error } \\
13.0155\end{array}$ & $\begin{array}{c}\boldsymbol{x}_{\mathbf{1}} \\
-5.6000\end{array}$ & $\begin{array}{c}x_{2} \\
7.2667\end{array}$ & $\begin{array}{c}\boldsymbol{x}_{\mathbf{3}} \\
-4.4000\end{array}$ & $\begin{array}{c}\boldsymbol{x}_{\mathbf{4}} \\
8.0667\end{array}$ & $\begin{array}{c}\text { error } \\
12.9844\end{array}$ \\
\hline$\vdots$ & $\vdots$ & $\vdots$ & $\vdots$ & $\vdots$ & $\vdots$ & $\vdots$ & $\vdots$ & $\vdots$ & $\vdots$ & $\vdots$ \\
\hline 22 & $\begin{array}{c}- \\
19.9999 \\
\end{array}$ & 13.7999 & $\begin{array}{c}- \\
17.9999 \\
\end{array}$ & 14.1999 & 0.00018845 & $\begin{array}{c}- \\
19.7499 \\
\end{array}$ & 13.8499 & $\begin{array}{c}- \\
18.2499\end{array}$ & 14.1499 & 0.00018821 \\
\hline \multirow[t]{2}{*}{$\begin{array}{c}\text { r/iterasi } \\
\text { ke n }\end{array}$} & \multicolumn{5}{|c|}{$r=0.8$} & \multicolumn{5}{|c|}{$\mathbf{r}=0.9$} \\
\hline & $\begin{array}{c}\boldsymbol{x}_{\mathbf{1}} \\
-5.4000\end{array}$ & $\begin{array}{c}\boldsymbol{x}_{\mathbf{2}} \\
7.4000\end{array}$ & $\begin{array}{c}\boldsymbol{x}_{\mathbf{3}} \\
-4.6000\end{array}$ & $\begin{array}{c}\boldsymbol{x}_{\mathbf{4}} \\
7.9333\end{array}$ & $\begin{array}{c}\text { error } \\
12.9622\end{array}$ & $\begin{array}{c}\boldsymbol{x}_{\mathbf{1}} \\
-5.2000\end{array}$ & $\begin{array}{c}\boldsymbol{x}_{\mathbf{2}} \\
7.5333\end{array}$ & $\begin{array}{c}\boldsymbol{x}_{\mathbf{3}} \\
-4.8000\end{array}$ & $\begin{array}{c}\boldsymbol{x}_{\mathbf{4}} \\
7.8000\end{array}$ & $\begin{array}{c}\text { error } \\
12.9488\end{array}$ \\
\hline$\vdots$ & $\vdots$ & $\vdots$ & $\vdots$ & $\vdots$ & $\vdots$ & $\vdots$ & $\vdots$ & $\vdots$ & $\vdots$ & $\vdots$ \\
\hline 22 & $\begin{array}{c}- \\
19.4999\end{array}$ & 13.8999 & $\begin{array}{c}- \\
18.4999\end{array}$ & 14.0999 & 0.00018804 & $\begin{array}{c}- \\
19.2499\end{array}$ & 13.9499 & $\begin{array}{c}- \\
18.7499\end{array}$ & 14.0499 & 0.00018794 \\
\hline \multirow[t]{2}{*}{$\begin{array}{c}\text { r/iteras } \\
\text { ke n }\end{array}$} & \multicolumn{10}{|c|}{$r=1$} \\
\hline & & $x_{1}$ & $x_{2}$ & & $r_{3}$ & $x_{4}$ & & & & \\
\hline 1 & & -5.0000 & 7.6667 & & 000 & 6667 & & 12. & 443 & \\
\hline$\vdots$ & & $\vdots$ & $\vdots$ & & $\vdots$ & $\vdots$ & & & & \\
\hline 22 & & -18.9999 & 13.9999 & -18 & 9999 & .9999 & & 0.000 & 1921 & \\
\hline
\end{tabular}


LAMPIRAN 2. Simulasi Pertama dengan Metode Iterasi Gauss-Seidel

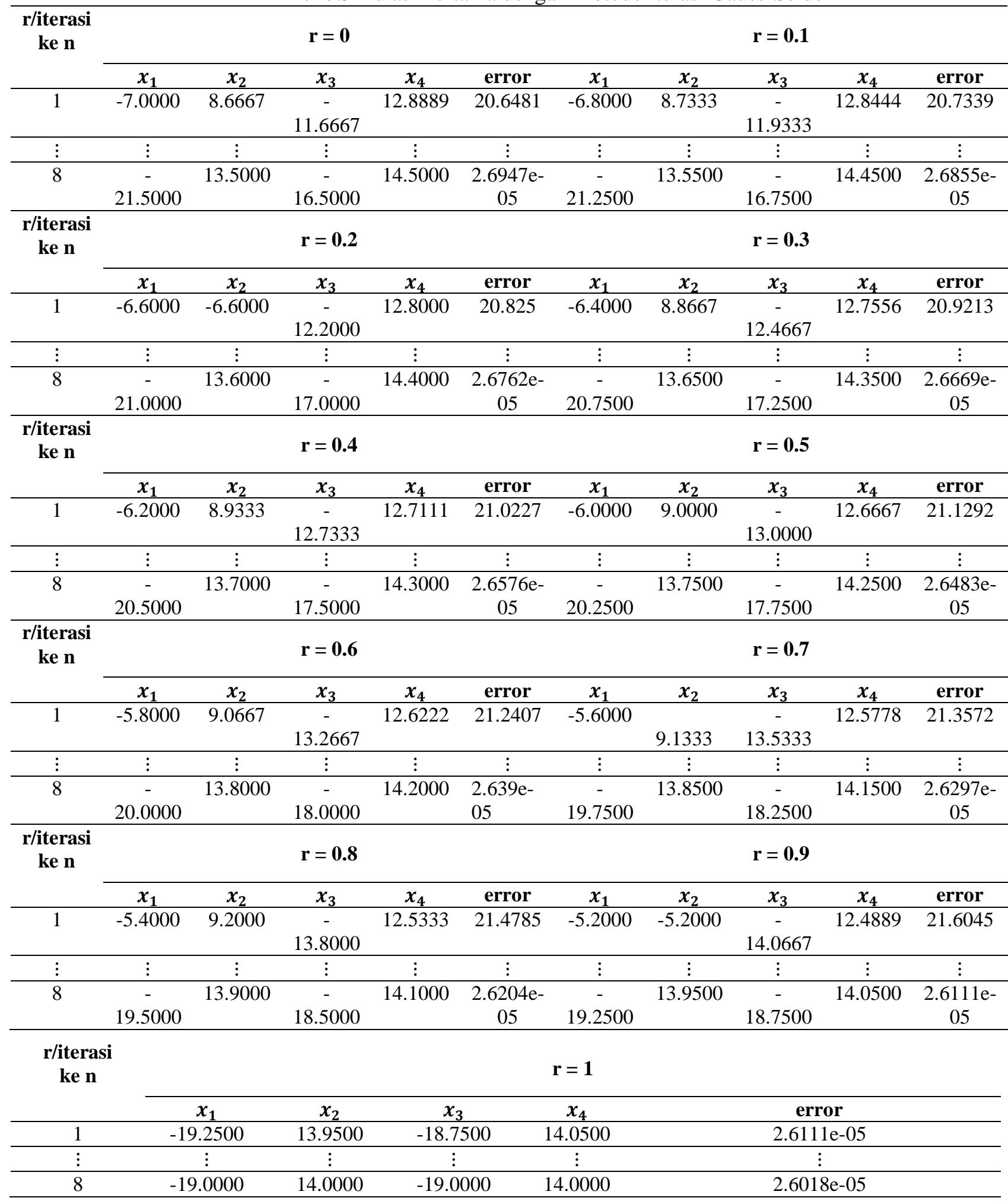


LAMPIRAN 3. Simulasi Pertama dengan Metode Iterasi Jacobi

\begin{tabular}{|c|c|c|c|c|c|c|c|c|c|c|}
\hline \multirow[t]{2}{*}{$\begin{array}{c}\text { r/iterasi } \\
\text { ke n }\end{array}$} & \multicolumn{5}{|c|}{$\mathbf{r}=\mathbf{0}$} & \multicolumn{5}{|c|}{$\mathrm{r}=0.1$} \\
\hline & $x_{1}$ & $x_{2}$ & $x_{3}$ & $x_{4}$ & error & $x_{1}$ & $x_{2}$ & $x_{3}$ & $x_{4}$ & error \\
\hline 1 & 0.1667 & 0.3333 & 1.1667 & 0.6667 & 1.3944 & 0.2167 & 0.4333 & 1.3333 & 0.4667 & 1.4934 \\
\hline$\vdots$ & $\vdots$ & $\vdots$ & $\vdots$ & $\vdots$ & $\vdots$ & $\vdots$ & $\vdots$ & $\vdots$ & $\vdots$ & $\vdots$ \\
\hline 11 & 0.0000 & 0.3334 & 1.0000 & 0.3333 & 0.00017933 & 0.1743 & 0.3753 & 1.1457 & 0.0848 & 0.00019205 \\
\hline $\begin{array}{c}\text { r/iterasi } \\
\text { ke n }\end{array}$ & \multicolumn{5}{|c|}{$\mathrm{r}=0.2$} & \multicolumn{5}{|c|}{$r=0.3$} \\
\hline & $x_{1}$ & $x_{2}$ & $x_{3}$ & $x_{4}$ & error & $x_{1}$ & $x_{2}$ & $x_{3}$ & $x_{4}$ & error \\
\hline 1 & 0.2667 & 0.5333 & 1.5000 & 0.2667 & 1.6361 & 0.3167 & 0.6333 & 1.6667 & 0.0667 & 1.8121 \\
\hline$\vdots$ & $\vdots$ & $\vdots$ & $\vdots$ & $\vdots$ & $\vdots$ & $\vdots$ & $\vdots$ & $\vdots$ & $\vdots$ & $\vdots$ \\
\hline 11 & 0.3486 & 0.4172 & 1.2914 & -0.1638 & 0.0002104 & 0.5229 & 0.4591 & 1.4371 & $\begin{array}{c}- \\
0.4124 \\
\end{array}$ & 0.00023303 \\
\hline $\begin{array}{c}\text { r/iterasi } \\
\text { ke n }\end{array}$ & \multicolumn{5}{|c|}{$r=0.4$} & \multicolumn{5}{|c|}{$r=0.5$} \\
\hline & $x_{1}$ & $x_{2}$ & $x_{3}$ & $x_{4}$ & error & $x_{1}$ & $x_{2}$ & $x_{3}$ & $x_{4}$ & error \\
\hline 1 & $\begin{array}{c}- \\
6.2000 \\
\end{array}$ & 8.9333 & $\begin{array}{c}- \\
12.7333 \\
\end{array}$ & 12.7111 & 21.0227 & 0.4167 & 0.8333 & 2.0000 & $\begin{array}{c}- \\
0.3333 \\
\end{array}$ & 2.2314 \\
\hline$\vdots$ & $\vdots$ & $\vdots$ & $\vdots$ & $\vdots$ & $\vdots$ & $\vdots$ & $\vdots$ & $\vdots$ & $\vdots$ & $\vdots$ \\
\hline 11 & 0.6972 & 0.5010 & 1.5828 & -0.6609 & 0.00025884 & 0.8715 & 0.5429 & 1.7285 & $\begin{array}{c}- \\
0.9095\end{array}$ & 0.00028696 \\
\hline $\begin{array}{c}\text { r/iterasi } \\
\text { ke n }\end{array}$ & \multicolumn{5}{|c|}{$r=0.6$} & \multicolumn{5}{|c|}{$\mathbf{r}=0.7$} \\
\hline & $x_{1}$ & $x_{2}$ & $x_{3}$ & $x_{4}$ & error & $x_{1}$ & $x_{2}$ & $x_{3}$ & $x_{4}$ & error \\
\hline 1 & 0.4667 & 0.9333 & 2.1667 & -0.5333 & 2.4633 & 0.5167 & 1.0333 & 2.3333 & $\begin{array}{c}- \\
0.7333 \\
\end{array}$ & 2.705 \\
\hline$\vdots$ & $\vdots$ & $\vdots$ & $\vdots$ & $\vdots$ & $\vdots$ & $\vdots$ & $\vdots$ & $\vdots$ & $\vdots$ & $\vdots$ \\
\hline 11 & 1.0458 & 0.5848 & 1.8742 & -1.1581 & 0.00031678 & 1.2200 & 0.6268 & 2.0199 & $\begin{array}{c}- \\
1.4066 \\
\end{array}$ & 0.00034786 \\
\hline $\begin{array}{c}\text { r/iterasi } \\
\text { ke n }\end{array}$ & \multicolumn{5}{|c|}{$r=0.8$} & \multicolumn{5}{|c|}{$r=0.9$} \\
\hline & $x_{1}$ & $x_{2}$ & $x_{3}$ & $x_{4}$ & error & $x_{1}$ & $x_{2}$ & $x_{3}$ & $x_{4}$ & error \\
\hline 1 & 0.5667 & 1.1333 & 2.5000 & -0.9333 & 2.9541 & 0.6167 & 1.2333 & 2.6667 & $\begin{array}{c}- \\
1.1333 \\
\end{array}$ & 3.2089 \\
\hline$\vdots$ & $\vdots$ & $\vdots$ & $\vdots$ & $\vdots$ & $\vdots$ & $\vdots$ & $\vdots$ & $\vdots$ & $\vdots$ & $\vdots$ \\
\hline 11 & 1.3943 & 0.6687 & 2.1656 & -1.6552 & 0.0003799 & 1.5686 & 0.7106 & 2.3113 & $\begin{array}{c}- \\
1.9037 \\
\end{array}$ & 0.00041267 \\
\hline \multirow[t]{2}{*}{$\begin{array}{c}\text { r/iterasi } \\
\text { ke n }\end{array}$} & \multicolumn{10}{|c|}{$r=1$} \\
\hline & & $x_{1}$ & $x_{2}$ & & $x_{3}$ & $x_{4}$ & & & error & \\
\hline 1 & & 0.6667 & 1.333 & & 2.8333 & -1.3333 & & & 3.4681 & \\
\hline$\vdots$ & & $\vdots$ & $\vdots$ & & $\vdots$ & $\vdots$ & & & $\vdots$ & \\
\hline 11 & & 1.7429 & 0.752 & & 2.4570 & -2.1523 & & & .000446 & \\
\hline
\end{tabular}


LAMPIRAN 4. Simulasi Pertama dengan Metode Iterasi Gauss-Seidel

\begin{tabular}{|c|c|c|c|c|c|c|c|c|c|c|}
\hline \multirow[t]{2}{*}{$\begin{array}{l}\text { r/iterasi } \\
\text { ke n }\end{array}$} & \multicolumn{5}{|c|}{$\mathbf{r}=\mathbf{0}$} & \multicolumn{5}{|c|}{$r=0.1$} \\
\hline & $x_{1}$ & $x_{2}$ & $x_{3}$ & $x_{4}$ & error & $x_{1}$ & $x_{2}$ & $x_{3}$ & $x_{4}$ & error \\
\hline 1 & 0.1667 & 0.2778 & 1.0278 & 0.3241 & 1.1253 & 0.2167 & 0.3611 & 1.1528 & 0.0824 & 1.2301 \\
\hline$\vdots$ & $\vdots$ & $\vdots$ & $\vdots$ & $\vdots$ & $\vdots$ & $\vdots$ & $\vdots$ & $\vdots$ & $\vdots$ & $\vdots$ \\
\hline 4 & 0.0000 & 0.3333 & 1.0000 & 0.3333 & 0.00013361 & 0.1743 & 0.3752 & 1.1457 & 0.0848 & $3.3975 \mathrm{e}-05$ \\
\hline \multirow[t]{2}{*}{$\begin{array}{l}\text { r/iterasi } \\
\text { ke n }\end{array}$} & \multicolumn{5}{|c|}{$\mathrm{r}=0.2$} & \multicolumn{5}{|c|}{$r=0.3$} \\
\hline & $x_{1}$ & $x_{2}$ & $x_{3}$ & $x_{4}$ & error & $x_{1}$ & $x_{2}$ & $x_{3}$ & $x_{4}$ & error \\
\hline 1 & 0.2667 & 0.4444 & 1.2778 & $\begin{array}{c}- \\
0.1593\end{array}$ & 1.3881 & 0.3167 & 0.5278 & 1.4028 & $\overline{-}-4009$ & 1.5835 \\
\hline$\vdots$ & $\vdots$ & $\vdots$ & $\vdots$ & $\vdots$ & $\vdots$ & $\vdots$ & $\vdots$ & $\vdots$ & $\vdots$ & $\vdots$ \\
\hline 4 & 0.3486 & 0.3486 & 1.2914 & $\begin{array}{l}- \\
0.1638\end{array}$ & $6.566 \mathrm{e}-05$ & 0.5229 & 0.4590 & 1.4371 & $\begin{array}{c}- \\
0.4124 \\
\end{array}$ & 0.00016529 \\
\hline \multirow[t]{2}{*}{$\begin{array}{l}\text { r/iterasi } \\
\text { ke n }\end{array}$} & \multicolumn{5}{|c|}{$r=0.4$} & \multicolumn{5}{|c|}{$\mathrm{r}=0.5$} \\
\hline & $x_{1}$ & $x_{2}$ & $x_{3}$ & $x_{4}$ & error & $x_{1}$ & $x_{2}$ & $x_{3}$ & $x_{4}$ & error \\
\hline 1 & 0.3667 & 0.6111 & 1.5278 & $\begin{array}{c}- \\
0.6426 \\
\end{array}$ & 1.8041 & 0.4167 & 0.6944 & 1.6528 & $\begin{array}{c}- \\
0.8843 \\
\end{array}$ & 2.0419 \\
\hline$\vdots$ & $\vdots$ & $\vdots$ & $\vdots$ & $\vdots$ & $\vdots$ & $\vdots$ & $\vdots$ & $\vdots$ & $\vdots$ & $\vdots$ \\
\hline 4 & 0.6971 & 0.5010 & 1.5829 & $\begin{array}{c}- \\
0.6610 \\
\end{array}$ & 0.00026493 & 0.8714 & 0.5429 & 1.7286 & $\begin{array}{c}- \\
0.9095 \\
\end{array}$ & 0.00036456 \\
\hline \multirow[t]{2}{*}{$\begin{array}{c}\text { r/iterasi } \\
\text { ke n }\end{array}$} & \multicolumn{5}{|c|}{$r=0.6$} & \multicolumn{5}{|c|}{$\mathrm{r}=0.7$} \\
\hline & $x_{1}$ & $x_{2}$ & $x_{3}$ & $x_{4}$ & error & $x_{1}$ & $x_{2}$ & $x_{3}$ & $x_{4}$ & error \\
\hline 1 & 0.4667 & 0.7778 & 1.7778 & $\begin{array}{c}- \\
1.1259 \\
\end{array}$ & 2.2915 & 0.5167 & 0.8611 & 1.9028 & $\begin{array}{c}- \\
1.3676 \\
\end{array}$ & 2.5494 \\
\hline$\vdots$ & $\vdots$ & $\vdots$ & $\vdots$ & $\vdots$ & $\vdots$ & $\vdots$ & $\vdots$ & $\vdots$ & $\vdots$ & $\vdots$ \\
\hline 4 & 1.0457 & 0.5848 & 1.8743 & $\begin{array}{c}- \\
1.1581 \\
\end{array}$ & 0.0004642 & 1.2200 & 0.6267 & 2.0200 & $\begin{array}{c}- \\
1.4067\end{array}$ & 0.00056383 \\
\hline $\begin{array}{c}\text { r/iterasi } \\
\text { ke n }\end{array}$ & \multicolumn{5}{|c|}{$r=0.8$} & \multicolumn{5}{|c|}{$\mathbf{r}=0.9$} \\
\hline 1 & $\begin{array}{c}\boldsymbol{x}_{\boldsymbol{1}} \\
0.5667\end{array}$ & $\begin{array}{c}\boldsymbol{x}_{\mathbf{2}} \\
0.9444\end{array}$ & $\begin{array}{c}\boldsymbol{x}_{\mathbf{3}} \\
2.0278\end{array}$ & $\begin{array}{c}\boldsymbol{x}_{\mathbf{4}} \\
- \\
1.6093 \\
\end{array}$ & $\begin{array}{c}\text { error } \\
2.8133\end{array}$ & $\begin{array}{c}\boldsymbol{x}_{\mathbf{1}} \\
0.6167\end{array}$ & $\begin{array}{c}\boldsymbol{x}_{\mathbf{2}} \\
1.0278\end{array}$ & $\begin{array}{c}\boldsymbol{x}_{\mathbf{3}} \\
2.1528\end{array}$ & $\begin{array}{c}\boldsymbol{x}_{\mathbf{4}} \\
- \\
1.8509 \\
\end{array}$ & $\begin{array}{c}\text { error } \\
3.0817\end{array}$ \\
\hline$\frac{\vdots}{4}$ & $\frac{\vdots}{1.3943}$ & $\begin{array}{c}\vdots \\
0.6686\end{array}$ & $\begin{array}{c}\vdots \\
2.1657\end{array}$ & $\begin{array}{c}\vdots \\
- \\
1.6552\end{array}$ & $\begin{array}{c}\vdots \\
0.00066347\end{array}$ & $\begin{array}{c}\vdots \\
1.5686\end{array}$ & $\begin{array}{c}\vdots \\
0.7105\end{array}$ & $\begin{array}{c}\vdots \\
2.3114\end{array}$ & $\begin{array}{c}\vdots \\
- \\
1.9038\end{array}$ & $\begin{array}{c}\vdots \\
0.0007631\end{array}$ \\
\hline \multirow[t]{2}{*}{$\begin{array}{l}\text { r/iterasi } \\
\text { ke n }\end{array}$} & \multicolumn{10}{|c|}{$r=1$} \\
\hline & & $x_{1}$ & $x$ & & $x_{3}$ & $x_{4}$ & & & error & \\
\hline 1 & & 0.6667 & 1.1 & & 2.2778 & -2.0926 & & & 3.3535 & \\
\hline$\vdots$ & & $\vdots$ & $\vdots$ & & $\vdots$ & $\vdots$ & & & $\vdots$ & \\
\hline 4 & & 1.7428 & 0.75 & & 2.4571 & -2.1524 & & & .00086274 & \\
\hline
\end{tabular}

